\title{
Configurações
}

Revista de sociologia

\section{"A escola dos ciganos": contributos para a compreensão do insucesso e da segregação escolar a partir de um estudo de caso.}

"The gypsies school": contributions from a case study to understand school failure and segregation.

"L'école des Roms»: contribution d'une étude de cas à la compréhension de l'échec et ségrégation scolaire.

Pedro Abrantes, Teresa Seabra, Tiago Caeiro, Sofia Almeida e Raquel Costa

\section{OpenEdition}

\section{Journals}

\section{Edição electrónica}

URL: http://journals.openedition.org/configuracoes/3658

DOI: $10.4000 /$ configuracoes.3658

ISSN: 2182-7419

\section{Editora}

Centro de Investigação em Ciências Sociais

Edição impressa

Paginação: 47-66

ISSN: 1646-5075

\section{Refêrencia eletrónica}

Pedro Abrantes, Teresa Seabra, Tiago Caeiro, Sofia Almeida e Raquel Costa, " "A escola dos ciganos": contributos para a compreensão do insucesso e da segregação escolar a partir de um estudo de caso. », Configurações [Online], 18 | 2016, posto online no dia 30 dezembro 2016, consultado o 19 abril 2019. URL : http://journals.openedition.org/configuracoes/3658; DOI : 10.4000/configuracoes.3658 
Abrantes, Pedro; Seabra, Teresa; Caeiro, Tiago; Almeida, Sofia; Costa, Raquel - "A escola dos ciganos": contributos para a compreensão do insucesso e da segregação escolar a partir de um estudo de caso. Configurações, vol. 18, 2016, pp. 47-66

\title{
"A eSCOLA doS Ciganos": CONTRIBUtOS PARA a COMPREENSÃo dO INSUCESSO E DA SEGREgAÇÃO ESCOLAR A PARTIR DE UM ESTUDO DE CASO
}

\author{
PEDRO ABRANTES \\ Universidade Aberta \\ TERESA SEABRA** \\ ISCTE-IUL \\ TIAGO CAEIRO*** \\ CIES-IUL \\ SOFIA ALMEIDA**** \\ ISCTE-IUL \\ RAOUEL COSTA***** \\ ISCTE-IUL
}

\begin{abstract}
Resumo
$\mathrm{O}$ artigo analisa os percursos das crianças ciganas de uma escola do $1^{\circ}$ ciclo, em Lisboa, na qual esta população é francamente maioritária (cerca de $80 \%$ ), apontando pistas para uma intervenção transformadora. A partir de estudos anteriores sobre o tema e de uma pesquisa de terreno, na qual cruzámos análise documental, entrevistas e observação participante, procurámos descrever e compreender as taxas dramáticas de absentismo, insucesso e retenção, a concentração crescente de alunos ciganos neste estabelecimento de ensino e os parcos resultados das intervenções socioeducativas desenvolvidas no local, ao longo dos últimos anos.
\end{abstract}

Palavras-chave: ciganos; educação; insucesso escolar; segregação.

\footnotetext{
*Investigador do CIES-IUL, Email: pedro.abrantes@iscte.pt

**Investigadora do CIES-IUL Email:teresa.seabra@iscte.pt

***:Investigador do CIES-IUL Email: tcaeiro@gmail.com

****Mestranda de Educação e Sociedade (ISCTE-IUL) Email:sfsaa@iscte.p

*****Mestranda de Educação e Sociedade (ISCTE-IUL) Email: raquelborgescosta@hotmail.com
} 


\begin{abstract}
The gypsies' school": contributions from a case study to understand school failure and segregation

The article analyses the paths and perspectives of Roma children in a Lisbon primary school, where this population is in large majority. Based on previous studies on this topic and on a field work, mixing documental analysis, interviews and participant observation, we describe and interpret the dramatic rates of absenteeism, failure and retention, the increasing concentration of Roma people in this school and the low impacts of the social and educational interventions developed locally.
\end{abstract}

Keywords: roma; education; school failure; segregation.

\title{
Résumé
}

"L'école des Roms»: contribution d'une étude de cas à la compréhension de l'échec et ségrégation scolaire

Cet article analyse les parcours et les perspectives des enfants Roms dans une école primaire à Lisbonne, où cette population est franchement majoritaire. Soutenu par des études antérieures sur ce sujet et par une recherche de terrain, dans laquelle nous avons utilisé l'analyse documentaire, les entretiens et l'observation participante, nous essayons de décrire et de comprendre les taux dramatiques de l'absentéisme, de l'échec et du redoublement, ainsi que la concentration croissante des Roms dans cet établissement scolaire et les maigres résultats obtenus par les interventions socio-éducatives y menées.

Mots-clés : roms ; éducation ; échec scolaire ; ségrégation.

\section{Introdução}

Quatro décadas após 1974, sabemos que a instituição escolar se democratizou substantivamente, como comprova a elevação dos níveis de escolaridade alcançados pela população portuguesa, apesar de persistirem desigualdades sociais no acesso aos níveis superiores de escolarização (Seabra et al., 2015) e de conhecermos a persistência da seletividade social do insucesso e abandono escolares. Para além deste tipo de desigualdades (marcadas, sobretudo, pela diferenciação dos níveis de escolaridade atingidos pelos progenitores), a trajetória escolar diferencia-se, ainda, pelas diferenciações de género, de ordem étnico-nacional ou regional.

No caso em análise, a pertença a um grupo étnico assume um lugar nuclear nas desigualdades escolares, estando estas igualmente associadas às condições sociais desfavorecidas: trata-se de crianças ciganas, residentes num bairro social da capital que se concentram numa escola do $1^{\circ}$ ciclo, tendo equidistantes outras 2 escolas do mesmo ciclo de escolaridade. Na comunidade local e entre os próprios agentes do sistema educativo, observou-se então a 
ideia de que esta se tornou "a escola dos ciganos”, classificação associada a um estigma que a própria escola não consegue superar e que leva a que as famílias não ciganas procurem "fugir" deste estabelecimento. Os níveis alarmantes de absentismo, insucesso e abandono nesta escola, a par do empobrecimento cultural e os riscos sociais associados à socialização das crianças e jovens em contextos culturalmente homogéneos, dentro de sociedades plurais, não deixa de nos levantar inúmeras inquietações.

A pesquisa representa o diagnóstico, realizado num agrupamento de escolas TEIP por uma equipa de peritos externos (autores do artigo), que teve como principais objetivos conhecer a situação escolar dos alunos de uma das escolas desse agrupamento (a que justifica a sua designação de TEIP), avaliar as condições de mudança dos problemas de insucesso e abandono escolares identificados à priori e, ainda, fazer recomendações de melhoria.

As questões que orientam o projeto são as seguintes:

- Como compreender que, num bairro central de uma grande cidade portuguesa, marcado pela diversidade sociocultural, exista uma escola frequentada quase exclusivamente pela população cigana, sem que exista qualquer política ou normativa que enquadre este processo?

- Como descrever e compreender os percursos escolares das crianças ciganas que frequentam esta escola, nomeadamente as taxas massivas de absentismo, insucesso e retenção, logo no $1^{\circ}$ ciclo de ensino?

- Como pode a investigação sociológica contribuir para que as crianças ciganas tenham percursos educativos bem-sucedidos, dentro de um sistema educativo orientado pelos princípios de igualdade de oportunidades, coexistência cultural e territorialização das políticas educativas e sociais?

\section{Enquadramento}

Apesar de a maioria dos relatórios sobre o sistema educativo português assumirem que as taxas de analfabetismo, absentismo e abandono escolares no ensino básico se tornaram residuais nas gerações mais jovens, sem fazer referencia à situação específica das populações ciganas, estudos realizados junto destas mostram que estes fenómenos continuam a ser massivos (Bastos, Correia e Rodrigues, 2007; Casa-Nova, 2008; Mendes, Magano e Candeias, 2014), o que, aliás, reforça os mecanismos de exclusão social.

O contraste entre os quadros culturais escolares e os dos ciganos tem sido apontado como um factor de incompreensão mútua, tensão e reprodução social que conduz ao insucesso e ao abandono escolares da generalidade destas crianças (Cortesão, 1994; Cortesão et al., 2005; Casa-Nova, 2008; Lopes, 2008; Abrantes, 2011; Bastos, 2012). 
Ainda assim, não devemos esquecer que mudanças societais de fundo como a democratização, a sedentarização, a urbanização, a escolarização, a solidariedade social e a regulação económica (incluindo restrições à venda ambulante), embora vividos como imposições externas, não deixaram de interpelar e transformar os modos de vida ciganos, no sentido de uma adaptação, evolução e flexibilização das tradições (Montenegro, 2012; Mendes, Magano e Candeias, 2014). A conversão maioritária à Igreja Evangélica de Filadélfia ou o uso das novas tecnologias da informação e da comunicação, entre outros processos, com maior força precisamente entre as gerações mais jovens, têm provocado tensões e mutações, inclusive nos valores, normas e solidariedades familiares, considerados frequentemente como o núcleo da cultura cigana. Esta abertura tem contribuído, aliás, para um aumento dos percursos de escolaridade na geração mais jovem, ainda que em décalage face ao verificado noutros grupos.

Também a suposta homogeneidade desta comunidade deve ser questionada. Se a venda ambulante constitui ainda a atividade laboral mais comum e culturalmente privilegiada, muitas famílias caracterizam-se por outros modos de vida (Mendes, Magano e Candeias, 2014). Além de uma elite bem estabelecida e integrada (Sousa, 2013), existem ciganos que tiveram trajetórias sociais ascendentes e que se encontram hoje na classe média, ainda que alguns deles ocultem a sua identidade étnica para se proteger de diferentes formas de discriminação. Existe, ao invés, um grupo crescente que não encontra ocupação e subsiste com base em apoios sociais e da própria comunidade. A diferenciação e a tensão entre as famílias ciganas é, aliás, um dos principais fatores que marca a "deriva cigana", entendida enquanto processo de diferenciação identitária (Lopes, 2008), e que mina o surgimento de movimentos reivindicativos fortes (Bastos, Correia e Rodrigues, 2007). Esta diversidade é também visível na relação com a escola, nomeadamente através de um distanciamento entre famílias que já apostam na escolaridade dos seus filhos e aquelas que continuam a atribuir-lhe um papel marginal nos seus percursos, modos e projetos de vida (Casa-Nova, 2008).

Ao contrário do observado na generalidade da população, no caso das crianças e e dos jovens ciganos, são claramente as raparigas que enfrentam maiores obstáculos à escolarização, sendo que a larga maioria apenas frequenta o $1^{\circ}$ ciclo do ensino básico, uma vez que muitas famílias continuam a defender que, à entrada da adolescência, as raparigas devem recolher a casa para se proteger e preparar para o casamento (Casa-Nova, 2008; Montenegro, 2012; Mendes, Magano e Candeias, 2014). Porém, as relações de género têm-se vindo a transformar, com uma crescente afirmação das mulheres, ainda que raramente colocando em causa a imagem pública da dominação masculina (CasaNova, 2008; Magano e Mendes, 2013). Além disso, mesmo os setores mais conservadores revelam-se abertos, por exemplo, a soluções de escolarização 
em contextos mais protegidos, no bairro, entre ciganos ou separando rapazes e raparigas (Caré, 2010). Por seu lado, ao concentrarmo-nos na questão das raparigas não podemos perder de vista que os rapazes estão longe de apresentar percursos de escolarização longos, consistentes e bem sucedidos.

Por fim, a mudança, a ambivalência e a pluralidade têm igualmente marcado o sistema educativo. Ainda que mitigado, é importante reconhecer a existência de um movimento educativo democratizador, ao longo das últimas décadas, orientado pelos princípios de abertura cultural, inclusão social e diversificação das experiências educativas (Alves e Canário, 2004), com reflexos evidentes na ação de algumas escolas e professores, incluindo o desenvolvimento de práticas pedagógicas interculturais, associadas a processos de investigação-ação (Casa-Nova, 2002; Cortesão et al., 2005). Porém, não deixam de se observar, em muitas outras escolas, em práticas profissionais instituídas e até em orientações político-administrativas, um "daltonismo cultural" (Stoer e Cortesão, 1999), a par de mecanismos de distinção, hierarquização e segregação (Abrantes e Sebastião, 2010), cujo impacto nos percursos escolares tem variado de forma assinalável entre origens étnicas (Seabra, 2012). Poderosas dinâmicas político-mediáticas, apoiadas em estratégias de distinção das classes dominantes e de fechamento do corpo docente, têm produzido um endurecimento das lógicas escolares seletivas (Abrantes, 2011), com efeitos no aumento recente dos níveis de retenção (CNE, 2015) e na orientação de cada vez mais jovens socialmente desfavorecidos e culturalmente diferenciados para percursos vocacionais e profissionalizantes, durante o próprio ensino básico (Abrantes e Roldão, 2016). No caso dos estudantes ciganos, perpetuam-se processos institucionais de constituição de escolas e turmas segregadas, fruto da combinação de "estratégias de fuga" por parte das famílias não-ciganas e de estratégias compensatórias, assentes em princípios - supostamente pedagógicos - de "inadequação cultural" e "déficit psicossocial” das crianças ciganas (Araújo, 2016).

As "gramáticas" que orientam as concepções a as ações dos agentes escolares sobre a população cigana são, portanto, múltiplas (Caetano e Mendes, 2014). O próprio programa Territórios Educativos de Intenvenção Prioritária (TEIP), ao incidir em escolas em contextos sociais mais vulneráveis, não deixa de refletir estas ambivalências e tensões (Canário e Alves, 2001; Abrantes et al., 2013). Por um lado, providencia um conjunto de recursos e condições que algumas escolas beneficiaram para solidificar as suas dinâmicas organizacionais e a sua relação com as comunidades locais, incluindo a contratação de mediadores ciganos e as parcerias com instituições comunitárias. Por outro, a escassez e a curta duração dos recursos, assim como as dificuldades de construção de projetos adequados às populações locais e a recente orientação para os resultados escolares, têm limitado os impactos do programa ao nível da inclusão dos grupos mais marginalizados. 
A nível internacional, a questão da integração escolar e social das crianças ciganas tem sido também motivo de investigação e reflexão. Em vários países, incluindo a Espanha, a intervenção centrada na criação de escolas, programas e serviços educativos específicos para a população cigana, ao longo do século XX, tem vindo a ser substituída pela plena integração destas crianças e jovens nas escolas e currículos regulares, sob um discurso de igualdade de oportunidades e combate à segregação, apoiado pelas próprias instituições europeias e mundiais (Bhopal, 2004; Garreta Bachaca, 2006; New e Merry, 2010). Contudo, os mesmos estudos reconhecem que o problema está longe de ser resolvido, com as taxas de insucesso e abandono escolar a manterem-se muito elevadas, devido a problemas de exclusão social, diferenciação cultural e discriminação, a que as políticas públicas, nomeadamente as educativas, não têm conseguido dar resposta.

Os estudos etnográficos de Levinson e Sparkes (2003 e 2005) são muito elucidativos, a este propósito, ao mostrar como o insucesso escolar das crianças ciganas está ancorado nas profundas tensões existentes entre as culturas escolar e familiar-comunitária, em referentes simbólicos tão estruturantes da vida quotidiana como as noções de tempo e de espaço, de masculinidade e feminilidade. Os autores mostram que o enfoque oficial nos resultados escolares acaba por esconder o facto de a resistência das crianças e jovens ciganos em aceitar as normas culturais resultar de processos de incompreensão mútua e, acima de tudo, de afirmação identitária e comunitária, ante um contexto envolvente considerado hostil.

Apesar deste cenário geral, alguns estudos têm procurado identificar, analisar e difundir "boas práticas", seja no desenvolvimento de programas e organizações escolares mais inclusivas e capazes de lidar com as diferenças socioculturais, seja na organização de atividades extracurriculares para as crianças ciganas, providenciando apoio, orientação, valorização e abertura cultural (Bhopal, 2004; Messing, 2008; Flecha e Soler, 2013). A este propósito, um dos principais desafios encontrados tem sido o facto de, tanto as organizações educativas como as próprias populações ciganas, serem muito diversas, tornando-se impossível encontrar modelos eficazes em todos os contextos. Em qualquer caso, aspetos como o perfil e formação específica dos profissionais, o profundo envolvimento das famílias/comunidades e o apoio/reconhecimento de entidades externas são aspetos comuns a estas distintas "boas práticas”.

A este propósito, valerá a pena refletir sobre um projeto recente realizado numa escola espanhola, com uma maioria de alunos ciganos e que revelava taxas de absentismo, insucesso e abandono muito preocupantes (Flecha e Soler, 2013). A partir dos princípios da "aprendizagem dialógica", o projeto produziu uma transformação profunda da escola, através do envolvimento das famílias ciganas na vida escolar e, em poucos anos, as supostas resistências à frequência 
escolar dissiparam-se e os resultados académicos situam-se em linha com os de muitos outros contextos escolares no país.

\section{Notas Metodológicas}

Tendo sido convidados para uma consultoria ao agrupamento, ao abrigo do programa TEIP, considerámos prioritária a constituição de uma equipa no ISCTE-IUL, envolvendo investigadores e estudantes de mestrado, com o objetivo de realizar um diagnóstico inicial da situação da escola do $1^{\circ}$ ciclo que justifica a inserção do AE neste programa, de modo a serem equacionadas medidas para minimizar os problemas identificados.

Tal como acordado com a direção do agrupamento, este diagnóstico pretendeu descrever de forma rigorosa os percursos educativos e, nomeadamente, o quadro de absentismo, insucesso e abandono escolar massivos que se observa nesta escola, avançando algumas explicações sociológicas que permitam a definição de estratégias locais mais eficazes e inclusivas. Além da recolha de dados objetivos sobre o insucesso e absentismo, isto incluía relacioná-los com várias dimensões que sabíamos de estudos anteriores serem influentes, tais como: a origem sociocultural dos alunos, a relação das famílias com a escola, os sentidos atribuídos por alunos e famílias à escola, a qualidade das infraestruturas e equipamentos escolares, o projeto educativo do agrupamento, a liderança da escola e do agrupamento, o perfil, estabilidade e orientações do corpo docente, assim como os projetos socioeducativos em curso na escola e na comunidade local.

Posteriormente, ao apercebermo-nos da homogeneidade cultural observada nesta escola e que contrasta com a diversidade cultural observada no espaço circundante, gerando tensões evidentes tanto no corpo docente como na própria população local, assumimos que o diagnóstico deveria igualmente procurar compreender as causas e efeitos da composição social da escola, levando os próprios atores locais a incluir a questão da distribuição dos estudantes pelas várias escolas existentes no território nas suas estratégias de promoção do sucesso escolar.

A realização deste diagnóstico decorreu entre Abril e Junho de 2016 e combinou três técnicas clássicas de investigação social: a análise documental, a entrevista semi-estruturada e a observação participante (ver quadro 1). Possuindo também limitações evidentes, cada uma destes dispositivos de recolha de dados permite captar uma dimensão diferente da vida escolar, sendo particularmente interessante para a análise o cruzamento dos resultados obtidos por cada um deles. 
Quadro 1

Instrumentos e atores mobilizados para a recolha e análise da informação

\begin{tabular}{|c|c|c|}
\hline Técnicas & Fontes Principais & Tipo de Análise \\
\hline $\begin{array}{l}\text { Análise } \\
\text { documental }\end{array}$ & $\begin{array}{l}\text { Relatório TEIP 2014-15 } \\
\text { Avaliação Externa do Agrupamento da IGE } \\
2013 \\
\text { Plano Plurianual de Melhoria } 2015-17 \\
\text { Processos Individuais de todos os alunos da } \\
\text { escola }\end{array}$ & $\begin{array}{l}\text { Análise de } \\
\text { conteúdo } \\
\text { Quantitativa, } \\
\text { através do SPSS }\end{array}$ \\
\hline $\begin{array}{l}\text { Entrevistas } \\
\text { semi-directivas }\end{array}$ & $\begin{array}{l}\text { Junta de Freguesia dos Olivais } \\
\text { Secretariado Diocesano de Lisboa da Obra } \\
\text { Nacional Pastoral dos Ciganos } \\
\text { Equipa do Projeto Rua - Instituto de Apoio à } \\
\text { Criança } \\
\text { Representantes das Famílias e da Comunidade } \\
\text { Local }\end{array}$ & Qualitativa \\
\hline $\begin{array}{l}\text { Observação } \\
\text { participante }\end{array}$ & $\begin{array}{l}\text { Dezenas de visitas à escola } \\
\text { Organização de uma sessão de auscultação dos } \\
\text { alunos de cada uma das turmas, nas respetivas } \\
\text { salas de aula } \\
\text { Participação em } 3 \text { reuniões de professores } \\
4 \text { reuniões com a direção do agrupamento } \\
1 \text { reunião do grupo comunitário }\end{array}$ & Qualitativa \\
\hline
\end{tabular}

Em primeiro lugar, realizou-se um levantamento dos dados contidos nos processos dos alunos, construindo-se uma base de dados com a informação disponível.

Para conhecer a visão dos vários parceiros institucionais, realizaram-se entrevistas aos diversos elementos que intervêm direta ou indiretamente com as crianças e os jovens desta comunidade educativa. Num focus group com mulheres ciganas com filhos inseridos em diferentes escolas, realizado no próprio bairro, apreendemos representações, desafios e expectativas daquela população sobre a escolarização. A observação participante incidiu em diversas reuniões: com professores e educadores de infância na escola, com a direção do agrupamento e outros 
elementos por esta indicados, com o Grupo Comunitário, composto por 14 entidades com intervenção no território. Dinamizámos ainda sessões com os alunos, em cada uma das turmas, com o objetivo de recolher depoimentos dos mesmos sobre as suas representações da escola, vivências e aspirações, recorrendo a um questionário, a debates e à produção de textos e desenhos. O questionário incluiu algumas questões abertas que procuraram conhecer a opinião dos alunos sobre a escola que frequentavam ("o melhor da escola"; "o pior da escola"), as melhorias que sugeriam ("o que mudavas se tivesses uma varinha mágica”) e ainda as suas aspirações escolares e profissionais.

\section{Percursos e aprendizagens das crianças}

Damos agora conta do levantamento realizado quanto aos trajetos realizados pelos alunos (resultados académicos e assiduidade), considerando as turmas, os anos de escolaridade e o sexo dos alunos e quanto às suas aspirações escolares ${ }^{1}$. Desta análise destaca-se o seguinte:

i) uma perda de $27 \%$ dos alunos ao longo do ano, considerando os que que pediram transferência de escola (17) e os que não compareceram na escola ou o fizeram faltando a maioria dos dias letivos (19);

ii) uma "fuga dos brancos" (white flight), dado que 13\% dos alunos inicialmente inscritos pediram transferência, sendo apenas 1 de etnia cigana;

iii) $24 \%$ dos alunos que permaneceram inscritos não transitaram de $\mathrm{ano}^{2}$;

iv) $16 \%$ dos alunos faltaram mais de metade do ano e apenas pouco mais de metade dos alunos (54\%) teve assiduidade satisfatória, com menos de 30 faltas anuais;

v) $9 \%$ dos alunos que frequentaram as aulas (deram, no máximo, 50 faltas) não conseguiram transitar de ano.

Um olhar mais detalhado permite detetar diferenças entre os docentes, tanto na taxa de retenção como na assiduidade dos alunos: o docente 3 registou a melhor taxa de transição e, concomitantemente, teve alunos mais assíduos e ocorreu uma situação contrastante no que se refere à taxa de transição com o docente 1 (o docente 6 , por ter uma turma com perfil muito específico, não se considerou para a presente comparação). $\mathrm{O}$ docente 2 destaca-se pela baixa assiduidade dos seus alunos, sem que este facto se tenha refletido diretamente na taxa de reprovação.

1 Não foi possível reconstruir o trajeto de 7 alunos por não ter sido localizado o seu processo.

$2 \mathrm{O}$ valor médio da taxa de retenção e desistência nacional no $1^{\circ}$ ciclo do ensino básico ronda os $5 \%$ (Estatísticas da Educação 2014/2015) 


\section{Quadro 2}

Trajeto escolar dos alunos no ano letivo de 2015-16 por docente

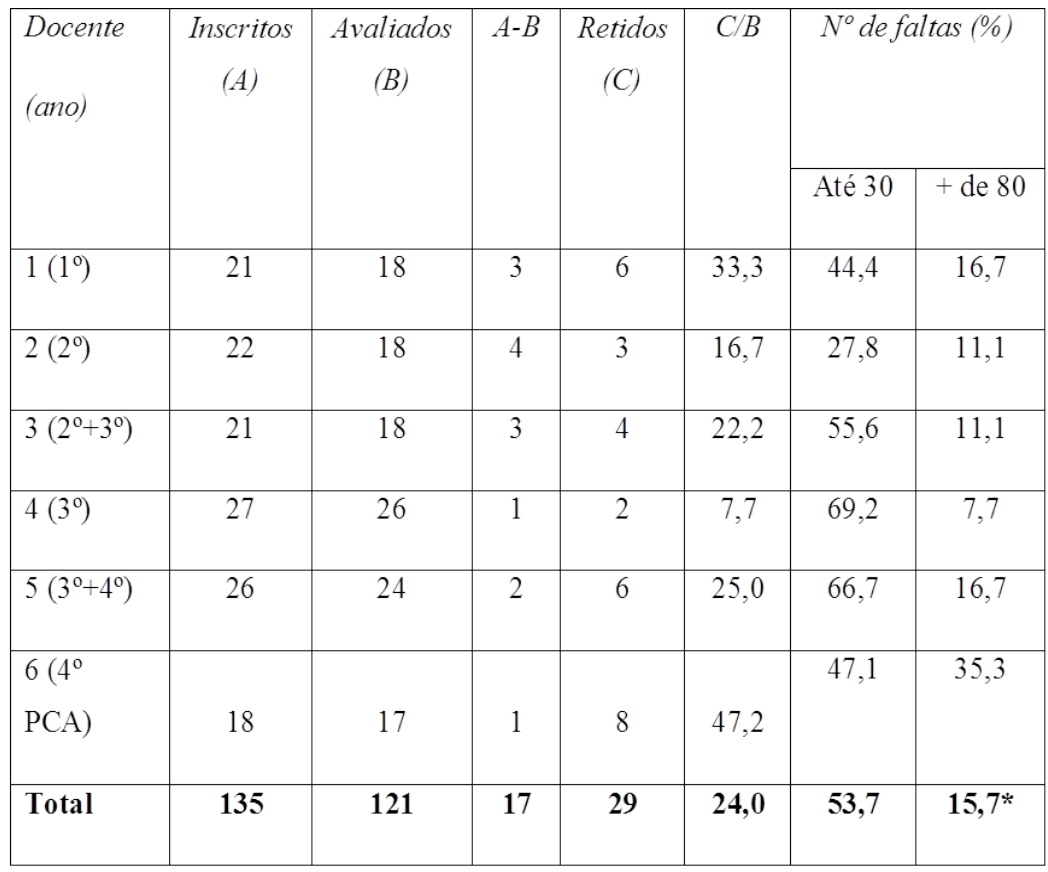

$* 3$ destes alunos transitaram ( 2 do $2^{\circ}$ ano e 1 do $3^{\circ}$ ano), apesar das faltas dadas

Estes alunos vivem em famílias de baixa escolaridade. As mães estão mais presentes do que os pais nos níveis de escolaridade da base e do topo do sistema de ensino. A grande maioria destas famílias $(80 \%)$ identifica-se como cigana e é reconhecida pela comunidade com tal, sendo que essa incidência tem vindo a aumentar de ano para ano, como é visível na análise do perfil dos alunos nos vários anos de escolaridade (quadro 3).

A incidência da reprovação é maior no início e no fim de ciclo mas, se restringirmos a análise ao conjunto de alunos que frequentaram com regularidade as aulas, não excedendo as 50 faltas anuais, concluímos que a taxa de reprovação se reduz em 15 pontos percentuais (de $24 \%$ para $9 \%$ ) e essa retenção incide exclusivamente no $2^{\circ}$ e $4^{\circ}$ ano de escolaridade. 
Quadro 3

Trajeto escolar dos alunos no ano letivo de 2015-16 por ano de escolaridade

\begin{tabular}{|c|c|c|c|c|c|c|c|c|c|}
\hline \multirow[t]{2}{*}{ Ano } & \multirow[t]{2}{*}{$\begin{array}{l}\text { Alunos } \\
\text { avaliados }\end{array}$} & \multicolumn{2}{|c|}{$\begin{array}{l}\text { Alunos } \\
\text { ciganos }\end{array}$} & \multicolumn{2}{|c|}{ Reprovação } & \multicolumn{2}{|c|}{$\begin{array}{l}\text { Alunos com } \\
\text { frequência } \\
\text { (até } 50 \text { faltas) }\end{array}$} & \multicolumn{2}{|c|}{$\begin{array}{l}\text { Alunos com } \\
\text { frequência que } \\
\text { reprovaram }\end{array}$} \\
\hline & & $\mathrm{N}^{0}$ & $\%$ & $\mathrm{~N}^{0}$ & $\%$ & $\mathrm{~N}^{0}$ & $\%$ & $\mathrm{~N}^{0}$ & $\%$ \\
\hline $1^{\circ}$ & 18 & 17 & 94,4 & 6 & 33,3 & 10 & 55,6 & 0 & 0,0 \\
\hline $2^{\circ}$ & 31 & 27 & 87,1 & 5 & 16,1 & 22 & 71,0 & 4 & 18,2 \\
\hline $3^{\circ}$ & 35 & 28 & 80,0 & 5 & 14,3 & 28 & 80,0 & 0 & 0,0 \\
\hline $4^{\circ}$ & 37 & 27 & 73,0 & 13 & 35,1 & 28 & 75,7 & 4 & 14,2 \\
\hline Total & 121 & 99 & 81,8 & 29 & 24,0 & 88 & 72,7 & 8 & 9,1 \\
\hline
\end{tabular}

A falta de assiduidade dos alunos, consensualmente considerado um problema nuclear, agrava-se à medida que progride a escolaridade, sobretudo no caso dos alunos que faltaram mais de $2 / 3$ do ano $\left(9 \%\right.$ no $3^{\circ}$ ano e $11^{\circ}$ no $4^{\circ}$ ano). Ao longo do percurso no $1^{\circ}$ ciclo, há uma progressiva configuração de situações extremadas, ou seja, de alunos que dão poucas ou muitas faltas. Igualmente preocupante é o contingente de faltas injustificadas: podemos constatar que a maioria das faltas é justificada (63\%), mas 19\% dos alunos tem 10 ou mais faltas injustificadas, o que, em rigor, teria como consequência a perda do RSI, nos casos em que este exista. Mais uma vez, é no $1^{\circ}$ e no $4^{\circ}$ ano que se encontram as situações mais preocupantes, sendo diminuto este problema no caso do $2^{\circ}$ ano. Ao grave problema do absentismo, acresce ainda a falta de pontualidade, cuja informação não é documentada de forma rigorosa e sistemática, mas as entrevistas e a observação participante deixaram antever que se trata de uma situação generalizada, sendo excecionais os casos dos alunos que estão na escola desde a hora de entrada até à hora de saída.

Numa análise mais detalhada constata-se que perto de metade dos alunos $(46 \%)$ excedeu as 30 faltas dadas ao longo do ano, vivendo uma situação de quase abandono ( 2 alunos do $4^{\circ}$ ano nunca marcaram presença). Os rapazes são menos assíduos que as raparigas (respetivamente, 33\% e $21 \%$ têm mais de 50 faltas), o que não se refletiu de forma negativa nas taxas de reprovação. No entanto, se observarmos as reprovações acumuladas ao longo 
do trajeto escolar, são os rapazes que acumulam trajetos mais penalizados pela repetência. Esta análise permitiu verificar que, no conjunto destes 121 alunos, até ao final do presente ano letivo, $78 \%$ dos alunos já tinha experimentado pelo menos 1 reprovação, ou seja, a probabilidade de um aluno que entra nesta escola não reprovar ao longo do seu $1^{\circ}$ ciclo é de cerca de $20 \%$ (quadro 4).

\section{Quadro 4 \\ Reprovação (pontual e acumulada) por sexo}

\begin{tabular}{|l|c|c|}
\hline & $2015-16$ & Desde o início da escolaridade \\
\hline Masculino & 23,3 & $\mathbf{7 9 , 7}$ \\
\hline Feminino & 24,6 & $\mathbf{7 5 , 4}$ \\
\hline Total & $\mathbf{2 4 , 0}$ & $\mathbf{7 7 , 5}$ \\
\hline
\end{tabular}

As classificações obtidas pelos alunos no final do ano letivo de 2015-16 (quadro 5) foram reveladoras de um melhor desempenho a matemática do que a língua portuguesa, dada a maior proporção de classificações de BOM, sendo, no entanto, igualmente desanimadora (um terço dos alunos) a proporção de alunos que não atingem um aproveitamento satisfatório em ambas as disciplinas.

\section{Quadro 5}

Classificação obtida pelos alunos no final do ano de 2015-16

\begin{tabular}{|l|c|c|c|c|}
\hline & Não satisfaz & Satisfaz & Bom & Muito Bom \\
\hline $\begin{array}{l}\text { Língua } \\
\text { portuguesa }\end{array}$ & 35,5 & 51,2 & 9.9 & 2,5 \\
\hline Matemática & 35,5 & 47,1 & 14,9 & 2,5 \\
\hline
\end{tabular}

Foi possível auscultar as crianças no que se refere às suas aspirações escolares, aspeto incluído no questionário que preencheram. No total de 38 alunos 
que indicaram uma meta concreta a atingir, perto de metade revelaram o desejo que ingressar no ensino superior (quadro 6). As ambições que não recobrem a atual escolaridade obrigatória de 12 anos correspondem a $28 \%$ destes alunos e são mais expressivas no ano inicial e no ano terminal deste ciclo de escolaridade.

\section{Quadro 6}

Aspirações escolares por ano de escolaridade

\begin{tabular}{|l|c|c|c|c|}
\hline \multirow{2}{*}{ Ano } & \multicolumn{3}{|c|}{ Aspirações escolares } & \multicolumn{2}{l|}{$\begin{array}{l}\text { Alunos } \\
\left(n^{0}\right)\end{array}$} \\
\cline { 2 - 4 } & $\begin{array}{c}\text { Até 90 } \\
\text { ano }\end{array}$ & $\begin{array}{c}\text { Até } \\
\text { secundário }\end{array}$ & $\begin{array}{c}\text { Curso } \\
\text { superior }\end{array}$ & \\
\hline $1^{0}$ & 3 & 4 & 2 & 9 \\
\hline $2^{0}$ & 2 & 1 & 6 & 9 \\
\hline $3^{0}$ & 1 & 3 & 5 & 9 \\
\hline $4^{0}$ & 2 & 4 & 5 & 11 \\
\hline Total & $\mathbf{8}$ & 12 & 18 & 38 \\
\hline
\end{tabular}

Os modos de expressão das metas a atingir por parte das crianças foi particularmente interessante quando estavam no início da escolaridade ( $1^{\circ}$ ano). Por exemplo, o João revelou a vontade de ser advogado e afirmou que queria estudar "o tempo todo", enquanto a Raissa escreveu que pretendia estudar: "Muitos anos! Mil anos!". Este modo difuso, mas bastante esclarecedor, adquiriu forma concreta na expressão dos colegas do $4^{\circ}$ ano que indicaram a Universidade ou a Faculdade como meta a atingir.

\section{Discussão}

No sentido de interpretar estes resultados, exploramos aqui quatro distintas linhas de análise. 


\subsection{Práticas educativas e dinâmicas culturais}

As reuniões realizadas com a direção do agrupamento e com o corpo docente permitem-nos concluir que, apesar de trabalharem diariamente e há vários anos nesta escola, não existe um conhecimento aprofundado da comunidade local, nem uma estratégia consistente de redução dos contrastes entre a cultura escolar e as culturas familiares.

Tal como em vários estudos anteriores sobre o tema (Levinson e Sparkes, 2005; Cortesão et al., 2005; Garreta Bachoca, 2006; Casa-Nova, 2008; Flecha e Soler, 2013), o absentismo e o insucesso escolar massivos desta população são interpretados como resultado do desinteresse pela escola e da sua falta de preparação (ou inferioridade) cultural. Considera-se que as famílias ciganas não valorizam a escolaridade e, por isso, não se levantam a horas para trazerem os filhos à escola, não cuidam do material escolar, não pressionam os filhos para serem assíduos e pontuais. Existem alguns docentes - como é o caso da coordenadora da escola - com algum conhecimento da comunidade e uma boa relação com esta, mas, mesmo nestes casos, persiste a visão de que os ciganos não conseguem atingir os mesmos padrões de aprendizagem que os restantes, pelo que a única solução seria assumir um ensino diferenciado logo desde o $1^{\circ}$ ano (o que não seria autorizado pela tutela). Genericamente, considera-se que estes alunos são enquadráveis na categoria de alunos com necessidades educativas especiais (NEE). Na mesma linha de raciocínio, a avaliação é entendida como contextual, pois a maioria dos docentes, apesar das elevadas taxas de insucesso, diz utilizar critérios de exigência bastante menores do que em outras escolas, valorizando o esforço e os progressos (mesmo que insuficientes) de alguns alunos.

Nenhum dos professores teve formação específica para trabalhar com populações ciganas, o que foi identificado em diversos estudantes anteriores como condição fundamental para o êxito dos projetos (Bhopal, 2004; Messing, 2008; Montenegro, 2012). Nenhum tem conhecimento de metodologias pedagógicas adequadas a este grupo. Contudo, adotam estratégias de ensino-aprendizagem bastante variadas, em função das suas convicções e experiências anteriores noutras escolas. Numa reunião, os professores concordaram que, caso os alunos ciganos não tivessem problemas de pontualidade e assiduidade, quase todos conseguiriam ter sucesso escolar. Existe um reconhecimento de que, dentro da sala de aula, realizam as tarefas solicitadas, mas ao chegarem tarde e ao faltarem com frequência, acabam por não conseguir acompanhar a sequência dos currículos escolares.

\subsection{Seleção e segregação na rede escolar pública}

Em linha com as atuais orientações políticas e jurídicas, a nível nacional e internacional (Garreta Bochaca, 2006; New e Merry, 2010; Mendes, Magano e Candeias, 2014), o facto de a escola ser quase exclusivamente frequentada por 
alunos ciganos é visto como algo negativo pela generalidade dos entrevistados. Contudo, existem divergências quanto às causas deste fenómeno e à possibilidade de este ser alterado.

A direção do agrupamento argumenta que uma parte das famílias ciganas quer inscrever os filhos nesta escola e as restantes não realizam as inscrições dentro dos prazos previstos ou não têm vaga noutros estabelecimentos, sendo reencaminhadas para esta escola devido à sua área de residência. Por seu lado, reconhece que a generalidade dos pais não-ciganos procura que o seu filho não fique nesta escola, conseguindo vaga noutras escolas das imediações, processo que se tem tornado mais fácil devido à diminuição do número de crianças na zona.

As mães entrevistadas declararam que algumas famílias pretendem colocar os filhos noutras escolas e, apesar de realizarem as inscrições no período previsto, acabam por ver recusadas essas pretensões. As responsáveis da Pastoral que têm acompanhado este bairro confirmam que algumas escolas da zona não aceitam crianças ciganas, dando o argumento do atraso nas matrículas, mas que frequentemente não corresponde à verdade. Acrescentam que as famílias ciganas, a partir do momento que têm um filho nesta escola, tendem a permanecer e a inscrever lá os filhos mais novos, pois não querem lidar com várias escolas ao mesmo tempo. Os responsáveis da junta de freguesia reconhecem que muitas famílias ciganas procuram inscrever os seus filhos noutras escolas, mas estas raramente as aceitam, e consideram que a distribuição dos alunos por diferentes escolas e turmas heterogéneas seria a solução mais adequada, tanto em termos sociais como educativos.

Importa assinalar que o bairro se situa numa localização equidistante de três escolas públicas do $1^{\circ}$ ciclo (duas delas pertencentes ao mesmo agrupamento), sendo difícil em qualquer dos casos que as crianças se desloquem sozinhas, não apenas pela distância aos estabelecimentos, mas, sobretudo, por ser uma zona com vários viadutos e outros obstáculos urbanos. No caso da outra escola pública do agrupamento, é frequentada por uma população socialmente heterogénea (mas sem ciganos), incluindo alguns alunos que frequentaram esta escola, geralmente no jardim-de-infância, mas que, entretanto, conseguiram transferência. Além disso, o próprio bairro social no qual vive a população cigana é também composto por famílias não-ciganas, tendo estas conseguido colocação noutras escolas da zona.

\subsection{Condições materiais e simbólicas da escola}

A escola dispõe de instalações sólidas e espaços exteriores amplos, numa zona habitacional tranquila, de vivendas, alguns prédios modernos, o mercado e, recentemente, uma estação de metro. Além disso, o edifício foi construído nos anos 1970, segundo um projeto arquitetónico inovador e com preocupações sociais e pedagógicas. 
Passados cerca de 40 anos de funcionamento, as instalações apresentam-se deterioradas e os espaços exteriores carecem de equipamentos recreativos. Há vários anos que está prevista uma intervenção estrutural, por parte da câmara municipal, que permita reabilitar o edifício e os recreios, incluindo a construção de um pavilhão gimnodesportivo, mas esta tem sido sucessivamente adiada e os agentes locais desconhecem os motivos. Enquanto se aguarda por essa intervenção, acaba por se adiar os pequenos trabalhos de pintura, manutenção e reparação que tornariam a escola mais aprazível.

Esta situação não deixa de ser muito penalizadora para a escola, também de um ponto de vista simbólico, até porque a outra escola do $1^{\circ}$ ciclo do agrupamento, situada a cerca de 250 metros, beneficiou recentemente de um programa de reabilitação que tornou as suas instalações e espaços exteriores muito apelativos. Possui dois parques infantis e dois campos de futebol em bom estado, jardins bem tratados, um chafariz onde as crianças se podem refrescar e vários caixotes do lixo, o que faz com que a escola esteja limpa e tenha uma imagem agradável.

Tudo isto contrasta com a escola em análise, onde as crianças salientam que o edificio precisa de obras, os materiais estão estragados, o telhado está sujo, o teto deixa entrar água, carece de produtos de higiene, as casas de banho e os balneários têm algumas torneiras sem funcionar. No recreio, existe apenas um espaço asfaltado com duas balizas, o chão encontra-se frequentemente sujo, existem vidros na areia onde brincam, o jardim não está arranjado e não existe um chafariz. Não é de estranhar que as crianças tenham apresentado a degradação das instalações e a falta de equipamentos de recreio como causa do insucesso, do absentismo e da desmotivação. Desafiados a fazer um desenho com a escola que gostariam de ter, quase todos incluíram baloiços, escorregas e outros equipamentos que existem na escola mais próxima. Os técnicos de intervenção social reforçam esta ideia, ao assinalar que estas crianças não dispõem, em casa ou no bairro, de brinquedos e de equipamentos recreativos, pelo que a sua existência na escola é fundamental.

\subsection{Intervenções sócio-educativas}

Embora haja sinais de crescente degradação e segregação, os fracos resultados académicos da escola e a sua associação à população cigana já estão sinalizados há muitos anos. A integração no programa TEIP, em 2006, é justificada pelos agentes locais pela situação observada nesta escola. A junta de freguesia também revela grande preocupação por uma situação que considera grave. A Santa Casa da Misericórdia tem uma presença importante no bairro, até por garantir o acompanhamento das famílias beneficiárias do rendimento social de inserção, cuja atribuição depende da frequência escolar dos menores. A Pastoral tem uma intervenção junta da população cigana neste território, desde os anos 1970, assumindo o problema da escolarização como dos desafios 
centrais. E o Projeto Rua, do Instituto de Apoio à Criança, também tem reforçado, nos últimos anos, a intervenção com os menores do bairro, sendo a sua escolarização um dos principais objetivos.

Não obstante a intervenção destas várias instituições ao longo das últimas décadas, não tem tido impactos muito evidentes na alteração dos padrões de escolarização das crianças ciganas, apresentados no ponto 3. A intervenção tende a revelar-se temporária e compensatória, sem conseguir instituir os princípios de interculturalidade (Garreta Bachoca, 2006). Não querendo colocar em causa o esforço dos profissionais no terreno e de forma ainda meramente exploratória, podemos apontar três elementos relevantes para compreender estes resultados, à luz de outras intervenções melhor sucedidas noutros contextos (Bhopal, 2004; Messing, 2008; Flecha e Soler, 2013).

Em primeiro lugar, a intervenção das várias entidades surge notavelmente fragmentada e de curto prazo para a dimensão e complexidade do problema. Ou seja, cada instituição tem desenvolvido um conjunto de ações, num quadro de escassez de recursos e de âmbitos de atuação específicos, mas nunca parece ter existido um projeto de intervenção que as envolvesse numa estratégia integrada e de médio/longo prazo. Muitos dos responsáveis e técnicos das diferentes instituições revelam alguma frustração e descrença acerca da capacidade de desenvolver uma ação que permita resolver a situação, mas não equacionam a possibilidade de uma iniciativa conjunta. Apesar de ser positiva a constituição de um grupo comunitário que integra estas várias instituições, este órgão tem funcionado, sobretudo, para a partilha de informação entre técnicos.

Em segundo lugar, não tem havido uma intervenção estruturada por parte de entidades de âmbito nacional, regional ou municipal para combater esta situação que transcenda a atribuição de alguns recursos extra às organizações locais. Organismos como o Ministério da Educação, a Segurança Social, a Câmara Municipal, entre outros, têm meios para desenvolver uma estratégia mais consistente e alargada. Pelo contrário, algumas decisões que provêm destas instituições - como é o caso de se ter beneficiado a outra escola no processo de reabilitação, enquanto se adiava indefinidamente a intervenção nesta escola - parecem ter contribuído para um agravamento dos problemas.

Por fim, não tem sido também possível a mobilização da população cigana local e, em particular, de alguns dos seus agentes mais influentes, na construção de soluções mais integradas. Não existem quaisquer mecanismos de auscultação e envolvimento da comunidade, nem estruturas de representação. No próprio grupo comunitário não está representado qualquer morador do bairro. 


\section{Considerações finais}

O estado atual das condições de escolarização observadas neste estudo documenta a amplitude da distância que falta percorrer na aproximação a um dos desideratos sociais da Escola nas sociedades modernas - a igualdade de oportunidades - ao mesmo tempo que convoca o debate acerca do papel do Estado na regulação dos bens públicos. Se o princípio da segregação foi formalmente revogado do sistema educativo português, tal como em toda a Europa, a sua concretização na prática, a par de outros princípios como o reconhecimento da diversidade cultural, a convivência intercultural e o sucesso escolar para todos, permanecem longínquos (Garreta Bachoca, 2006; New e Merry, 2010; Mendes, Magano e Candeias, 2014).

Temos a noção de que o contexto em análise neste artigo corresponde a um "caso limite", não espelhando a situação na maioria das escolas portuguesas, nem sequer o ambiente de escolarização da maioria das crianças ciganas. Contudo, a sua existência não deixa de interpelar a investigação sociológica, não apenas no sentido de poder contribuir para uma intervenção local que se afigura urgente, mas também para a compreensão de processos mais transversais à sociedade contemporâneas e que permitem a emergência (e manutenção) deste tipo de situações, em alguns territórios.

Estando demonstrados os benefícios da mistura social na mobilização e na mobilidade social dos grupos sociais mais vulneráveis (Duru-Bellat, 2002;Seabra, 2010; Seabra et. al, 2015), é recorrente a resistência dos grupos sociais que, no contexto local, estão em melhores condições de controlar as dinâmicas de afetação dos alunos e dos recursos materiais e humanos, na convicção de que o eventual benefício de "outros" se traduziria no prejuízo dos próprios. Por seu lado, a segregação social dos "públicos" não deixa de estar associada a um processo de degradação material e simbólica dos estabelecimentos de ensino que servem as populações mais desfavorecidas e estigmatizadas, o que não sendo evidente no início do processo, vai contudo contribuindo para uma polarização das experiências, oportunidades e resultados.

Além disso, observa-se ainda uma apropriação tradicionalista e monocultural das orientações curriculares, sem esforços consistentes de contextualização às realidades locais ou envolvimento das comunidades nos processos de ensinoaprendizagem, mesmo quando estas apresentam notáveis contrastes culturais, sendo que os próprios recursos adicionais disponibilizados especificamente para o combate ao insucesso e ao abandono escolar, além de se revelarem parcos e de curto prazo, face à amplitude do problema, são mobilizados apenas numa vertente compensatória e pouco ajustada às necessidades, condições e interesses das populações ciganas (Levinson e Sparkes, 2005; Flecha e Soler, 2013). Também a articulação entre a intervenção educativa da escola e de outras instituições sociais com presença no território local surge desarticulada, o que prejudica os seus resultados. 
Assim sendo, estando perante um campo social que é atravessado por múltiplas tensões decorrentes da luta de interesses dos diferentes grupos em presença, importa equacionar as modalidades de intervenção articulando as forças em presença com a garantia de a sociedade potenciar ao máximo as oportunidades dos mais desfavorecidos.

Sabemos que a mudança social implica a mobilização de múltiplos agentes multisituados e, neste caso, será igualmente central "aproveitar" as experiências bem sucedidas (em território nacional ou fora deste), concertando a atuação dos profissionais e demais agentes da comunidade local. Só assim se poderá contribuir para a coesão social, a igualdade de oportunidades e o diálogo intercultural.

\section{Referências}

ABRANTES, P. e J. Sebastião (2010), "Portões que se abrem e que se fecham: Processos de inclusão e de segregação na escola pública portuguesa”, in A. Dornelas et al. (orgs.), Portugal Invisível, Lisboa, Mundos Sociais.

ABRANTES, P. (2011), "Revisitando a teoria da reprodução: debate teórico e aplicações ao caso português”, Análise Social, XLVI (199), pp. 261-281.

ABRANTES, P., C. Roldão, P. Amaral e R. Mauritti (2013), "Born to fail? Some lessons from a national programme to improve education in poor districts”, International Studies in Sociology of Education, 23 (1), pp. 17-38.

ABRANTES, P. e C. Roldão (2016). "Old and new faces of segregation of Afro-descendant population in the Portuguese education system: a case of institutional racism?”, Conferência Educação Comparada para Além dos Números, SPCE-SEC, Lisboa, 25-27 de Janeiro.

ALVES, N. e Canário, R. (2004). “Escola e exclusão social: das promessas às incertezas”. Análise Social, 38 (169), pp. 981-1010.

ARAÚJO, M. (2016), A very 'prudent integration': white flight, school segregation and the depoliticization of (anti-)racismo. Race, Ethnicity and Education, 19 (2), pp. 300-323.

BASTOS, J. Pereira; A. Correia e E. Rodrigues (2007), Sintrenses ciganos. Uma abordagem estrutural - dinamica, Lisboa, Câmara Municipal de Sintra e ACIDI.

BASTOS, J.Pereira (org.) (2012), Portugueses Ciganos e Ciganofobia em Portugal, Lisboa, Edições Colibri.

BHOPAL, K. (2004). "Gypsy Travellers and Education: Changing Needs and Changing Perceptions”, British Journal of Educational Studies, 52 (1), pp. 47-64.

CAETANO, P. e M. M. Mendes (2014), "Shaping ways of managing diversity in Portuguese schools, from the student's perspective”, International Review of Sociology, 24 (2), pp. 325-344.

CANÁRIO, R., N. Alves e C. Rolo (2001), Escola e Exclusão Social: Para uma Análise Crítica da Política TEIP, Lisboa, Educa/IIE.

CARÉ, M.J. (2010), Ciganos em Portugal: Educação e Género, Dissertação de Mestrado, Lisboa, Instituto de Educação da Universidade de Lisboa.

CASA-NOVA, M.J. (2002), Etnicidade, género e escolaridade. Estudo em torno das socializações familiares de género numa comunidade cigana do Porto, Lisboa, IIE.

CASA-NOVA, M. J. (2008), Família, etnicidad, trabajo y educacion. Estúdio etnográfico sobre los modos de vida de una comunidad gitana del Norte de Portugal, Tesis de Doctoral por compendio, Universidad de Granada. 
CNE - Conselho Nacional de Educação (2015), Retenção Escolar nos Ensinos Básico e Secundário, Lisboa, CNE.

CORTESÃO, L. (1994), “Quotidianos marginais desvendados pelas crianças”, Educação, sociedade e culturas, 1, pp. 63-87.

CORTESÃO, L. e S. Stoer (1999), Levantando a Pedra - Da Pedagogia Inter/Multicultural às Políticas Educativas numa Época de Transnacionalização, Porto, Edições Afrontamento.

CORTESÃO, L., S. Stoer, M. J. Casa-Nova e R. Trindade (2005), Escola e Comunidade Cigana: Representações Recíprocas, Lisboa, ACIME.

DGEEC-MEC (2014). Estatísticas da Educação 2012/2013. Lisboa: Autor.

DURU-BELLAT, M. (2002), Les inegalités sociales á l'école - genèse et mites, Paris, PUF.

FLECHA, R. e M. Soler (2013), “Turning difficulties into possibilities: engaging Roma families and students in school through dialogic learning”, Cambridge Journal of Education, 43 (4), pp. 451-465.

GARRETA BOCHACA, J. (2006), "Ethnic minorities and the Spanish and Catalan educational systems: from exclusion to intercultural education”, International Journal of Intercultural Relations, 30 (2), pp. 261-279.

LEVINSON, M. P. e A. C. Sparkes (2003), “Gypsy Masculinities and the School-Home Interface: exploring contradictions and tensions”, British Journal of Sociology of Education, 24 (5), pp. 587-603,

LEVINSON, M. P. e A. C. Sparkes (2005), “Gypsy children, space, and the school environment”, International Journal of Qualitative Studies in Education, 18 (6), pp. 751-772,

LOPES, D. Seabra (2008), Deriva Cigana: Um Estudo Etnográfico sobre os Ciganos de Lisboa, Lisboa, ICS.

MAGANO, O. e M. Mendes (2013), "Mulheres ciganas na sociedade portuguesa: tracejando percursos de vida singulares e plurais”, SURES, 3, pp. 1-15.

MESSING, V. (2008), "Good practices addressing school integration of Roma/Gypsy children in Hungary”, Intercultural Education, 19 (5), pp. 461-473

MENDES, M., O. Magano e P. Candeias (2014), Estudo Nacional sobre as Comunidades Ciganas, Lisboa, ACM.

MONTENEGRO, M. (2012), Aprender a Ser Cigano, Hoje: Empurrando e Puxando Fronteiras, Doutoramento em Educação, Instituto de Educação da UL.

NEW, W. S. e M. S. Merry (2010), “Solving the 'Gypsy Problem': D.H. and Others v. the Czech Republic”, Comparative Education Review, 54 (3), pp. 393-414

SEABRA, T. , C. Roldão, S. Mateus e A. Albuquerque (2015), Caminhos escolares de jovens africanos (PALOP) que acedem ao ensino superior, CIES-IUL/ACM.

SEABRA, T., M.M. Vieira, P. Ávila, L. Castro, I. Baptista e S. Mateus (2014). Escolas que fazem melhor: o sucesso escolar dos descendentes de imigrantes na escola básica, FCT, CIES-IUL.

SEABRA, T. (2010), Adaptação e Adversidade: O Desempenho Escolar dos Alunos de Origem Indiana e Cabo-Verdiana no Ensino Básico, Lisboa, Imprensa de Ciências Sociais.

SEABRA, T. (2012), "Desigualdades de desempenho escolar: etnicidade, género e condição social em escolas básicas da AML”, Sociologia - Revista da Faculdade de Letras da Universidade do Porto, Número temático: Imigração, Diversidade e Convivência Cultural, pp. 185-210.

SOUSA, C. J. (2013), Os Maias: Retrato Sociológico de uma Família Cigana Portuguesa (18271957), Lisboa, Mundos Sociais. 